hold good, although it has some relation to the cause of the hardening of moti referred to in (1). Moti, when once hardened, can begin to soften at a temperature somewhat below the transition point, and the water of moti is connected with its hardness. These facts show that the constitution below and above the transition point is not the only factor in the determination of hardness.

(4) My views (J. Phys. Chem., 31, 933; 1927: Zement, 19,$842 ; 1930)$ on the mechanism of the setting and hardening of cement are to a great extent applicable also to the hardening process of moti. In brief, the hardening is due to the decrease of free water in the system. In the case (la) above, free water in moti escapes to the exterior. In the case $(1 b)$, free water which exists at higher temperatures loses its freedom in cooling, becoming water of erystallisation, adsorbed water, ete. It may be that the transition point $63.5^{\circ} \mathrm{C}$. is connected with the water of erystallisation. As to the water of crystallisation in starch, the opinion of St. v. Náray-Szabó (Zeit. physik. Chem., A, 151, 420; 1930) is suggestive. Details of this work will appear in the Scientific Papers of this Institute.

The Institute of Physical and Tutomu Maeda. Chemical Research,

Hongo-Komagome, Tokyo, Japan, Jan. 31.

\section{Geo-electrical Prospecting.}

IN my article published in NATURE of Jan. 3 of this year, entitled "Geo-electrical Prospecting by A.C. Bridge Methods", I stressed a disadvantage of the well-known A.C. equipotential line method of prospecting, which is sometimes so serious as to preclude the use of the method altogether. The difficulty arises from the fact that large out-of-phase components occur in the neighbourhood of the more highly conducting ore-bodies and that in such circumstances it is impossible to locate equipotential points with any degree of accuracy. In extreme cases there are no distinguishable minima from which the general trend of the current distribution may be determined.

I am writing to direct attention to a means of overcoming this difficulty which was recently suggested to me by D. C. Gall, who at the time was visiting one of my field parties. He proposed that a small search coil should be placed in series with the detecting circuit, which usually consists of a pair of pointed rods connected by 50 feet or so of wire to an amplifier and headphone. Since the e.m.f. induced in the coil will be in quadrature with the current, whereas that in the ground is approximately in phase with the current, it was to be expected that by suitably orientating the search coil it would be possible to balance the out-of-phase component and so locate the in phase equipotential points with precision.

Mr. Gall's suggestion has now been tried out and has proved most satisfactory, and there can be no doubt that it constitutes an improvement in the equipotential line method which will prove of great practical value. In the tests recently carried out, the coil was permanently attached to the amplifier box on the back of the operator. The latter, by slightly adjusting the position of his body, can quickly bring the coil into such a position that the equipotential points may be accurately located on the ground; complete silence being observed in the telephones.

A. Broughton Edge.

Australia House,

Strand, London, W.C.2, Mar. 17.

No. 3203, Vor.. 127]
Enumeration of Magic Squares of the 5th Order.

\begin{tabular}{r|rrrr|r}
\multicolumn{5}{c}{$A$} \\
25 & 8 & 5 & 24 & 3 \\
7 & 16 & 9 & 14 & 19 \\
6 & 11 & 13 & 15 & 20 \\
4 & 12 & 17 & 10 & 22 \\
\hline 23 & 18 & 21 & 2 & 1
\end{tabular}

\begin{tabular}{r|rrr|r}
\multicolumn{5}{c}{$B$} \\
25 & 21 & 2 & 7 & 10 \\
17 & 1 & 22 & 16 & 9 \\
14 & 18 & 13 & 8 & 12 \\
3 & 20 & 4 & 15 & 23 \\
\hline 6 & 5 & 24 & 19 & 11
\end{tabular}

\begin{tabular}{|c|c|}
\hline \multicolumn{2}{|l|}{$C$} \\
\hline $\begin{array}{lll}15 & 18 & 6\end{array}$ & 1214 \\
\hline $16 \quad 122$ & 215 \\
\hline 82011 & 323 \\
\hline $\begin{array}{lll}9 & 2 & 19\end{array}$ & 2510 \\
\hline 17 & \\
\hline
\end{tabular}

In NATURE of Oct. 17, 1925, p. 573 , I gave the above, but I was not then able to give the number of squares of $B$ and $C$. I can now complete this. $A$ has a 'Heart' magic in its 3 rows, 3 columns, and 2 diagonals, and with its 21 positions inside a square of 5 th order has 649,168 squares. $B$ has a 'Heart' with only its 3 rows, 3 columns magic, and with its 21 positions of all proportions from $52 / 13-26 / 39$ has 720,388 squares. $C$ has a 'Heart' without the number 13, and in its 18 positions has 3656 squares.

Including all types of squares thus far, I have brought the grand total of magic squares of 5 th order, whose 5 rows, 5 columns, and 2 diagonals are magic, to $1,623,768$. One type only has one solitary square, but this type can be transformed by inversion into three other types, with their complementary squares of the proportion 52/13, each having a solitary square. I give it as unique :

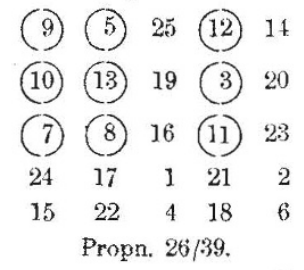

Barkston,

Nr. Grantham, Lines, Feb. 6.

Climatic Control in the Reproductive Cycle.

IN my letter in Nature of Feb. 7, p. 200, entitled "Embryology and Evolution", I referred to a correlation between magnetic solar radiation and the reproduction of fur-bearing animals. Statements to the effect that such a correlation has been proved to exist are frequent, and are also found in certain text-books, but there seems to be considerable doubt as to their validity.

I have, therefore, sought to obtain reliable evidence on this subject, and I am indebted to the Governors and Committee of the Hudson's Bay Company, and to Mr. Charles Elton, of Oxford, for information which is of value in showing that such a correlation was originally suggested by Mr. Elton in 1924 as an hypothesis only, and that it has erroneously been elevated gradually by others to the rank of fact.

I am informed by the Hudson's Bay Company that its trading operations are not based on the indications of sunspot activity nor on those of other meteorological conditions; while Mr. Elton's view is that though sunspot influence has to be ruled out definitely, there is, nevertheless, some proof of climatic control in the reproduction cycle of fur-bearers.

The phenomenon of photoperiodicity in plants might well be substituted in my original argument as an example of an external control in the activities of the living cell.

Wellcome Field Laboratory, MalColm E. MacGregor. Wisley, Surrey. 